\title{
Application of Big Data in E-Commerce Marketing based on 4R Model
}

\author{
Jianghui Liu ${ }^{1}$, Yingying Liang ${ }^{2}$, and Shuping Lin $^{3}$ \\ ${ }^{1}$ Education Technology Center, Experimental Teaching Center, Guangdong University of Foreign \\ Studies, Guangzhou, China \\ ${ }^{2}$ School of Economics and Trade, Guangdong University of Foreign Studies, Guangzhou, China \\ ${ }^{3}$ School of Information Science and Technology, Guangdong University of Foreign Studies, \\ Guangzhou, China \\ 247031690@qq.com
}

Keywords: Big Data, E-Commerce, 4R Marketing Theory

Abstract: Based on Big Data background and 4R Marketing Theory, this study analysed the efficient marketing model of E-Commerce enterprises. Through explaining the concept of Big Data and 4R Marketing Theory, and analysing the E-Commerce overview, we established four marketing paths from the aspects of relevance, reaction, relation, and reward. Finally, we integrated above paths to build an efficient marketing model for ECommerce companies. This study provides theoretical support for the realization of the profit target of E-Commerce enterprises.

\section{Introduction}

With the development of Internet technology, the amount of data shows an explosive growth. Big Data has attracted the attention of all walks of life. Relying on the Internet platform, ECommerce enterprises accumulate various types of data, customer purchase information, commodity transaction volume, and so on. These data bear the information of different customer groups and become the core assets of enterprises (Feng Liu, 2014). The application of data is becoming the core competitive elements of enterprises. To efficiently complete the data collection, selection, processing and analysis, has become the key marketing effect (Ping Cheng, Shuo Zhang, 2015). Meanwhile, the choice of scientific and advanced marketing theory is an effective guarantee of successful marketing. The 4R Marketing Theory is an advanced marketing idea that helps businesses and customers to build a close relationship, to reduce the cost of operating and to achieve a win-win situation. Guided by the 4R Marketing Theory, combined with the technology of data, E-Commerce enterprises are more easily to grasp the market dynamics, to seize the opportunity and realize the long-term development, even in the fierce market competition situation. 


\section{The Explanation of Concepts}

\subsection{Big Data}

Recently, with the development of technology, all kinds of information data can be stored and transmitted rapidly. We have ushered in the age of Big Data. Big Data, which believes "everything is quantifiable", is characterized by abundant information and comprehensive content. The development of the Big Data has, to some extent, improved the asymmetrical phenomena in the market. The quantifiable data also brings a range of opportunities to the enterprise and becomes a new productivity for enterprise growth.

\subsection{R Marketing Theory}

Since the beginning of the 21st century, the market competition has become more and more intense, and the win-win thought has formed a guiding ideology. The theory of 4C, focusing on what customers need, is gradually incapable to fitting the marketing situations (Tingting Wang, Huan Hou, 2015). American scholar Don Schulz put forward the 4R Marketing Theory on the basis of summarizing the previous theory (Feng, Liu, 2014). This theory mainly consists of four aspects: customer Relevance, market Reaction, Relationship and Reward. The competition-oriented 4R Marketing Theory focuses on but is not blind to meet customer needs. It guides the enterprise to establish a long-term and solid relationship with customers. At the same time, it suggests corporation to pay attention to market changes, in order to improve the speed of market response. And then, enterprises are easier to conduct relationship marketing and realize profit returns. Marketing activities are carried out from four aspects of 4R theory to achieve win-win results for both enterprises and customers.

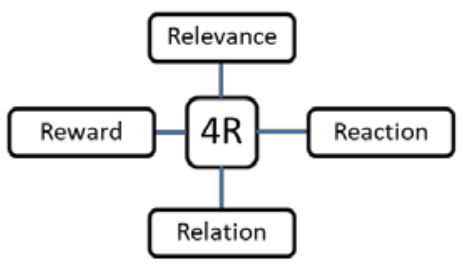

Figure 1 4R Marketing Theory Model.

\section{General analysis of E-Commerce marketing based on 4R Marketing Theory in Big Data} ERA

\subsection{E-Commerce Marketing}

With Internet as the platform and Internet technology as the tool, the marketing activities of enterprises are E-Commerce marketing. Thanks to the efficient network, strong interactivity, low cost and other characteristics, E-Commerce is developing rapidly. Many people have made their fortunes by E-Commerce, such as Jack Ma who earned a lot by establishing a huge E-Commerce platform-TaoBao. However, because of the gradual popularization of Internet technology and the low barriers of E-Commerce market, E-Commerce businesses have mushroomed contributing the increasingly intense market competition. 


\subsection{The Importance of 4R Theory in E-Commerce Marketing Application}

In Big Data era, E-Commerce now is facing a complex market environment. To stand out from the billions of E-Commerce, it is an essential task to learn from advanced marketing theories and explore marketing strategies that meet the characteristics of E-Commerce enterprises. Lacking competitive orientation and paying little attention to the interaction between buyers and sellers, the limitations of 4P and 4C marketing theories have exposed in today's marketing practice (Xuehan, Zhao, 2015). Nowadays, 4R Marketing Theory is one of the advanced marketing theories. It emphasizes that the enterprise needs to create a new type of initiative relationship between the enterprise and the customer in an effective way, and to focus on the mutual benefit both of the buyers and the sellers (Yanfang, Feng, 2015). At the same time, the 4R theory reflects the requirements of marketing activities in a more comprehensive way. It is a guarantee for achieving good marketing results and an important guiding theory for E-Commerce marketing (Yi, Sun, 2015. Yuxin, Zhao, Yanping, Wang and Lei Guan, 2018).

\section{Construction of Efficient Marketing Model of E-Business Enterprise Based on 4R Theory in Big Data Age}

In Big Data era, efficient marketing based on 4R theory refers that company uses big data technology and 4R theory to achieve high -efficiency marketing. Using Big Data, enterprises can quickly collect and screen large quantities of information, establish a database, and make market analysis, so as to build marketing paths from four aspects of Relevance, Reaction, Relationship and Reward, as shown in Figure 2.

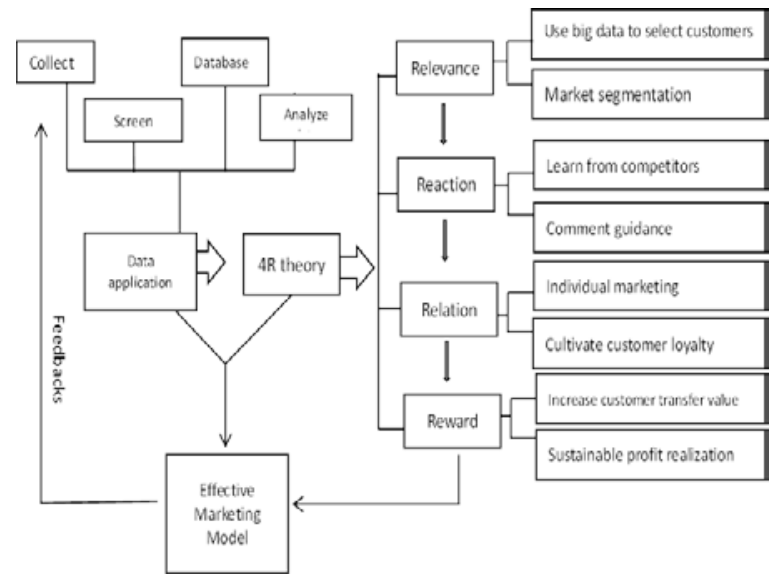

Figure 2 Construction of E-Business Marketing Model Based on 4R Theory in Big Data.

This model is based on Big Data analysis process, with data application as the core and 4R Marketing Theory as the guidance. It is a closed-loop model covering three stages of data application process, specific marketing paths and information collection of marketing processes.

\subsection{The Relevance Path of E-Commerce Enterprises in Big Data Era}

\subsubsection{Make Full Use of Big Data to Accurately Select Target Customers}

In marketing practice, accurate customer positioning is the beginning of marketing. Only after selecting target customers can E-Commerce operators establish the direction of development and obtain expected economic and social benefits. With the help of the data, the user information database is established, the audience information is selected, and potential customers are grasped. 
Meanwhile, the company can know the market trend by clicking and purchasing data of products to provide the product portfolio that meets market requirements. On this basis, solid relationships with customers are built through the satisfactory product as a media.

\subsubsection{Market Segmentation}

Today, most of enterprises that focus on short-term interest are restricted to cater to the need of most people. This directly resulted in the homogenization, and the widespread phenomenon of marketing. Such poor marketing strategies inevitably ignore the differences of different customer groups and the diversification of buyer's demand which lead to loss of profit.

\subsection{The Reaction Path of E-Commerce Enterprises in Big Data Era}

\subsubsection{Learn from Competitors}

It is said that know the enemy and know yourself, and you can fight a hundred battles with no danger of defeat. In order to emerge in E-Commerce, it is not only necessary to analyse the data of the enterprise itself, but also to analyse the data of competitors. By analysing the information related to the business activities of competitors, E-Commerce enterprises can figure out the advantages and disadvantages of others. Afterwards, company can imitate others' strengths as much as possible to make up own weaknesses, so as to improve their services, products as well as marketing model.

Besides, based on the analysis of rivals, the corporation can be more aware of its market position, and better predict the opportunities and challenges of the future market which enables company to make early adjustments, and successfully run the enterprise.

\subsubsection{Customer Feedback and Comment Guidance}

Customers directly experience the marketing activities. Their satisfaction and dissatisfaction directly reflect the effects of marketing activities. Therefore, it is very important to collect customers' feedback information in time. E-Commerce can rely on the Internet platform to conduct research on customers, get to know whether or not customers are satisfied with products and services, timely solve problems. Meanwhile, enterprises are suggested to attach importance to customers' improvement suggestions, aiming at constantly improve customers' marketing experience and the quality of enterprise operation.

In particularly, due to the virtualization of E-Commerce enterprises, customers cannot truly perceive products. So, other buyers' evaluations have great impact on customers' purchasing decisions. Without doubt, positive feedback can add value to products. Enterprises can also introduce positive comments to customers more actively with the aim to increase sales. It is possible for a business operator to increase sales by doing that. For instance, an online bookstore can make full use of douban.com and various book reviews from BBS to let the buyers get more positive information about the targeted book.

\subsection{The Relationship Path of E-Commerce Enterprises in Big Data Era}

\subsubsection{Individual Marketing}

In the case of serious product homogenization, personalized marketing has become an important strategy for E-Commerce to meet customers' differentiated demands and get more customers. It allows E-Commerce to gain commercial profits and promote the establishment of long-term 
relationships with customers. Personalized marketing and above market segmentation are complementary. Besides obtaining data such as customers' consumption habits, consumption frequency and purchase preferences, E-Commerce should also collect relevant natural attributes of customers, including monthly income, cultural tendency and so on. After that, E-commerce can establish Big Data analysis model by integrating all information, in order to take customers' interests and purchasing ability into account and make accurate and effective recommendation and guidance for customers. In fact, Taobao's "guess what you like" is the application of personalized marketing.

\subsubsection{Cullivate Customer Loyalty}

If customers purchasing behaviour only happens once, from the long-term interests of the enterprise, such buying is of little significance. To make customers willing to buy again, it is necessary for E-Commerce to establish a long-term close relationship with customers and cultivate more loyal clients. 4R Marketing Theory emphasizes the importance of interaction between enterprises and customers, which is an important way to cultivate customer loyalty. With the developed social media technology, in addition to the inherent customer service system of the online store, E-Commerce can also establish customer social groups on social media, such as WeChat, QQ and other platforms. In social groups, customers can share comments on products with each other to result new sales. Sellers can also release new products and other announcements in social groups to propaganda timely and accurately.

\subsection{The Reward Path of E-Commerce Enterprises in Big Data Era}

\subsubsection{Increase Customer Transfer Value}

The profit ultimately comes from customers. According to the 4R theory, enterprises should focus on a win-win situation between enterprises and customers. To increase customer transfer value is an indispensable task for enterprise. Customer transfer value refers to the differences between the total value of customer purchase and the total cost of customer purchase. Total purchase value includes product value, service value, personnel value, and so on. While the total cost of the customer refers to money, time and mental costs. Based on the above paths, the company can utilize large data, to provide target customers with individualized, differentiated products and services, which fundamentally improve the customer's total purchase value.

At the same time, relying on Big Data analysis and various social media platforms, E-Commerce are able to accurately provide product information to relevant customers and effectively reduce the time and energy of customers to search for products. Company should also make full use of Big Data to carefully compare various logistics systems, so as to select the most convenient logistics for customers and reduce the waiting time of customers. In these ways, the total cost of customers is reduced.

In addition, to further increase the customer transfer value, E-Commerce enterprises can conduct business in good faith to gain customer trust.

\subsubsection{Sustainable Profit Realization}

Whatever the marketing methods, the ultimate goal of enterprise is the enterprise profit. In the fierce market competition, it is inevitable for E-Commerce enterprises to pursue profits and implement low-cost strategies. The enterprise fully considers the price that the customer is willing to pay, minimizes the cost, and obtains more customers on this basis, realizes the scale benefit, then thus achieves a win-win result. 


\section{The necessity of Big Data in E-Commerce marketing based on 4R theory}

Many economists compare Big Data to hidden mines, showing that Big Data is of great value. The Big Data is not about the wealth of data, it's about using data to discovery value. For many industries, accurate use of these Big Data is a key to win a competition. Depending on the Internet, the E-Commerce business is dealing with a lot of real web users, with lots of user information including customers' buying habits, competitors' products and other information. The important factor of its core competitiveness is the utilization of Big Data.

In Big Data era, by analysing massive data, enterprises can accurately find target customers and segment their demands so that enterprises enable to establish close relationship with customers in an effectively way. In terms of reaction, by listening customer feedback, the company can make accurate prediction of the future market situation, seize the opportunity of product market and create greater profit. Besides, learning from competitors can help enterprises improve own products and services, and improve user experience. In terms of relationship building, Big Data is used to depict customers to know their personalized needs so that enhance customer loyalty and establish mutually beneficial relationships. As for return strategy, by fully analysing customer information, enterprise can accurately recommend appropriate products to customers. By doing the cost of customers is saved, and marketing cost of enterprises is greatly reduced. In general, through the application of Big Data, enterprises not only provide value for customers, but also reduce operating costs of enterprises. And through receiving constant feedback, the enterprises are able to perfect the product and realize the sustainable growth of profit.

\section{Future Research Works}

In the age of information explosion, data is very abundant. The structure of data is complex and irregular. The four paths of the above marketing model are based on accurate data analysis. In essence, the application of Big Data plays an important role in successful using the marketing model. Therefore, it is very necessary to study how to realize the effective application of data. For now, Hadoop is a distributed framework that effectively implements the precise application of large data. It realizes massive data storage and calculation of data. Besides, it improves marketing activities such as "customer image" and precision promotion. In the future, in order to make the greater value of Big Data, we will refine the data application process of marketing model integrating the Hadoop framework. Also, we will further elaborate the internal connection between data application processes and marketing paths. Afterwards, we are going to use the advanced model to establish the development path of domestic Time Banking, in the hope of making suggestions to solve the serious problems concerning the elderly care in China

\section{Conclusions}

In the era of Big Data, we are no longer satisfied with the traditional marketing model. Instead, we actively use Big Data technology and scientific marketing theories to help enterprises achieve high-efficiency marketing. In today's competitive marketing environment, E-Commerce can be guided by 4R theory in Big Data era, and attach importance to the association between enterprises and customers. E-Commerce enterprises should actively grasp market information to improve response speed. Using Big Data, enterprises establish a good relationship with customers through personalized marketing and interacting with customers. Meanwhile, enterprise can better achieve a win-win situation by improving customer transfer value. 


\section{References}

[1] Feng, Liu, 2014. TV Marketing in Big Data Era-a Study in the Perspective of 4I Principles of EIMC, East China Normal University.

[2] Ping, Cheng, Shuo, Zhang, 2015. Application of Cloud Accounting in Tax Business in Big Data Age, Friends of Accounting. 22, pp. 127-130.

[3] Tingting, Wang, Huan, Hou, 2015. The Challenges and Countermeasures on the E-Commerce Taxation in Big Data Era, Contemporary Economic Management. 8, pp. 78-85.

[4] Feng, Liu, 2014. Research on TV Media Marketing in Big Data Age, East China Normal University,

[5] Xuehan, Zhao, 2015. Research on Marketing Strategy of IP Drama from the Perspective of $4 R$ Theory, Heilongjiang University.

[6] Yanfang, Feng, 2015. Focus and Strategy of Marketing Efficiency Improvement in Big Data Age, Enterprise Economy. 11, pp. 57-61.

[7] Yi, Sun, 2015. Challenges and Responses to Tax Work in Big Data Era, Academic Exchang. 6, pp. 133-139.

[8] Yuxin, Zhao, Yanping, Wang and Lei Guan, 2018. Research on Precision Marketing Model of E-Business Enterprises under the Background of Big Data, Modern Business. 15, pp. 14-15. 